\title{
Epidemiology of participation: an Australian community study
}

Frances E Baum, Robert A Bush, Carolyn C Modra, Charlie J Murray, Eva M Cox, Kathy M Alexander, Robert C Potter

\begin{abstract}
Study objective-To determine the levels of participation in social and civic community life in a metropolitan region, and to assess differential levels of participation according to demographic, socioeonomic and health status. To contribute to policy debates on community participation, social capital and health using these empirical data.
\end{abstract}

Design-Cross sectional, postal, self completed survey on health and participation. Setting-Random sample of the population from the western suburbs of Adelaide, the capital city of South Australia, a population of approximately 210000 .

Participants-2542 respondents from a sample of 4000 people aged 18 years and over who were registered on the electoral roll.

Main results-The response rate to the survey was $63.6 \%(n=2542)$. Six indices of participation, on range of social and civic activities, with a number of items in each, were created. Levels of participation were highest in the informal social activities index (46.7-83.7\% for individual items), and lowest in the index of civic activities of a collective nature $(2.4-5.9 \%$ for individual items). Low levels of involvement in social and civic activities were reported more frequently by people of low income and low education levels.

Conclusions-Levels of participation in social and civic community life in an urban setting are significantly influenced by individual socioeconomic status, health and other demographic characteristics. An understanding of the pattern of participation is important to inform social and health policy making. Increasing levels of participation will reduce social exclusion and is likely to improve the overall quality of community life.

(F Epidemiol Community Health 2000;54:414-423)

Faculty of Humanities and Social Science, University of

Technology, Sydney

E M Cox

Women's and Children's Hospital, Adelaide, South

Australia

K M Alexander

Correspondence to: Professor Baum

(fran.baum@flinders.edu.au)

Accepted for publication 20 October 1999 els of trust and participation in a community are related to the degree of equity in income distribution and, together, contribute to improved population health outcomes. ${ }^{4}$ Participation is also viewed as a crucial component of "social capital", a concept that is currently the focus of many public policy debates. Despite a growing literature on community participation and social capital there remain many questions about implementation and measures of success. One of these questions concerns the range and types of participation that exist within specific populations.

For the purposes of this article the key issues of debate in the literature on participation are those regarding types, purposes and levels of participation and their measurement in a population. This literature will be reviewed and then followed by a consideration of the ways in which the issue of participation has been subsumed in broader considerations of the role of civil society in promoting health. Following this, data from an Australian suburban population will be used to investigate the types and levels of participation.

People can participate in their communities in all sorts of ways. Their participation can be in social groups or in activities that are more focused on civic matters. Most health literature views these types of participation from the perspective of an organisation, which is concerned to "increase community participation". ${ }^{5-7}$ A number of authors have commented that an organisational perspective on participation tends to be seen as either a means to achieving an end, or as a valuable health promoting activity in and of itself..$^{8-10}$ In this perspective participation can be seen as the means of achieving a set objective or goal. Legge ${ }^{9}$ calls this "instrumental" participation. There is less concern with the act of participation and more with the results of participation. The emphasis is on rapid mobilisation, direct involvement in the task at hand and the participation is abandoned once the task has been completed. An example would be if an external agency came to a community with a pre-determined programme related to a specific issue such as child safety, which required the programme implementers to work with the community. The participation would be limited, solely for the purpose of implementing the programme. Baum ${ }^{11}$ points out that this style of participation tends to be driven by outsiders to the community and rarely results in any shift of decision making power or resources from the outside implementers to local citizens and their representative agencies. 
Table 1 Levels of participation in informal social activities, by demographic and health characteristics of respondents

\begin{tabular}{|c|c|c|c|}
\hline & \multicolumn{3}{|c|}{ Type of informal social connection } \\
\hline & $\begin{array}{l}\text { Visited family/ } \\
\text { family visit } \% \text { (n) }\end{array}$ & $\begin{array}{l}\text { Visited friends/ } \\
\text { friends visit } \%(n)\end{array}$ & $\begin{array}{l}\text { Visited neighbours/ } \\
\text { neighbours visit \% (n) }\end{array}$ \\
\hline \multicolumn{4}{|l|}{ Gender } \\
\hline Men & $80.1(877)^{\star}$ & $79.7(876)$ & $45.5(500)$ \\
\hline Women & $86.6(1179)$ & $83.2(1118)$ & $47.7(644)$ \\
\hline \multicolumn{4}{|l|}{ Age (y) } \\
\hline $18-59$ & $85.5(1370)^{\star}$ & $84.8(1360)^{\star}$ & $42.2(677)^{\star}$ \\
\hline $60+$ & $80.3(654)$ & $75.4(604)$ & $55.7(448)$ \\
\hline $\mathrm{p}$ Value & 0.001 & 0.000 & 0.000 \\
\hline \multicolumn{4}{|l|}{ Education level } \\
\hline Low & $80.1(265)$ & $77.6(253)^{\star}$ & $58.0(189)^{\star}$ \\
\hline Medium & $84.1(1417)$ & $81.0(1360)$ & $45.9(770)$ \\
\hline High & $85.4(344)$ & $87.8(354)$ & $41.0(167)$ \\
\hline $\mathrm{p}$ Value & 0.068 & 0.000 & 0.000 \\
\hline \multicolumn{4}{|c|}{ Annual household income } \\
\hline$<\$ 15600$ & $79.1(606)^{\star}$ & $78.6(595)^{\star}$ & $51.6(393)^{\star}$ \\
\hline$\$ 15600-\$ 31199$ & $85.3(459)$ & $83.7(451)$ & $46.1(248)$ \\
\hline$\$ 31200-\$ 46799$ & $88.2(368)$ & $82.3(343)$ & $44.6(186)$ \\
\hline$\$ 46800-\$ 62399$ & $87.4(209)$ & $86.6(206)$ & $41.4(99)$ \\
\hline$\$ 62400+$ & $88.1(251)$ & $85.0(243)$ & $42.1(120)$ \\
\hline p Value & 0.000 & 0.002 & 0.000 \\
\hline \multicolumn{4}{|l|}{ Physical health $(<60)$} \\
\hline Low & $82.2(424)$ & $82.8(428)$ & $43.5(225)$ \\
\hline High & $87.3(897)$ & $86.3(886)$ & $41.6(428)$ \\
\hline $\mathrm{p}$ Value & 0.007 & 0.069 & 0.460 \\
\hline \multicolumn{4}{|c|}{ Physical health $(\geqslant 60)$} \\
\hline Low & $79.0(410)$ & $73.1(378)$ & $54.9(287)$ \\
\hline High & $83.5(187)$ & $80.7(180)$ & $59.5(131)$ \\
\hline $\mathrm{p}$ Value & 0.155 & 0.028 & 0.241 \\
\hline \multicolumn{4}{|l|}{ Mental health $(<60)$} \\
\hline Low & $79.8(276)^{\star}$ & $79.0(275)^{\star}$ & $37.2(130)$ \\
\hline High & $87.2(1045)$ & $86.9(1039)$ & $43.7(523)$ \\
\hline $\mathrm{p}$ Value & 0.001 & 0.000 & 0.033 \\
\hline \multicolumn{4}{|l|}{ Mental health $(\geqslant 60)$} \\
\hline Low & $71.1(101)^{\star}$ & $66.4(91)$ & $44.4(63)^{\star}$ \\
\hline High & $82.5(503)$ & $77.4(467)$ & $59.1(355)$ \\
\hline p Value & 0.002 & 0.007 & 0.001 \\
\hline \multicolumn{4}{|l|}{ Social isolation } \\
\hline Low & $87.4(1446)^{\star}$ & $85.2(1402)^{\star}$ & $50.2(826)^{\star}$ \\
\hline High & $75.8(561)$ & $73.7(546)$ & $39.1(291)$ \\
\hline p Value & 0.000 & 0.000 & 0.000 \\
\hline Total & $83.7(2056)$ & $81.6(1994)$ & $46.7(1144)$ \\
\hline
\end{tabular}

${ }^{\star} \mathrm{p}<0.006$ (Bonferroni correction of 9 ).

Participation can also be far more developmental in its aim. In this case, Oakley ${ }^{12}$ comments that the process is "dynamic, unquantifiable and essentially unpredictable". The participation is not limited to the life of a particular project but seen as a permanent and intrinsic feature of an organisation or community. The critical elements in the process are to increase the awareness of the people and develop organisational capacities. Engaged, ongoing participation produces the trust and networks that are the oil of social capital. ${ }^{13} 14$ Full, engaged participation does not happen easily. Oakley ${ }^{8}$ indicates that it may start off as marginal participation in which people have relatively little impact on the activity. This will especially be the case where the motivation for the project comes from outside the community. Baum $^{11}$ notes that structural participation (control by the community) will be evident where participation is integral and forms the basis for all activity. This is evident when local citizens play an active and direct part in the initiative and have the power to determine the direction and actions taken.

Despite a considerable literature on the types of participation in health, there is little that provides an insight in to which groups of a population are most likely to participate, and in which type of activity. Very few attempts have been made to examine the prevalence of participation in a population and to describe the patterns of participation across a population. There is some North American literature ${ }^{15}$ that reports on rates of political participation and the sociodemographic correlates. This literature does not, however, look at social participation or participation in community groups with less of a civic purpose. This study, however, considered participation in a broad perspective, seeing individuals' levels of participation in both social and civic affairs as important. It is consideration of both social and civil factors that makes the contribution of this paper novel. The past decade has seen the development of an extensive literature on the concept of empowerment through citizen participation and its significance to population health. Participation in social and civic life is a central factor to understanding empowerment. The interest in empowerment is reflected in literature from a number of disciplines relevant to public health including: radical social and community work, ${ }^{16-18}$ health promotion and education $^{19-25}$ and community psychology. ${ }^{26-28}$ Israel et al, based on a review of literature from a range of disciplines and professions, offer the following definition of empowerment:

"Empowerment, in its most general sense, refers to the ability of people to gain understanding and control over personal, social, economic and political forces in order to take action to improve their life situations. In contrast to reactive approaches that derive from a treatment or illness mode, the concept of empowerment is positive and proactive." ${ }^{29}$

The authors cited above agree that this sense of empowerment is determined in part by the extent to which people participate in activities outside their immediate home and work lives that is in the domain of civil society. In the current public policy environment in which the allocative role of the state is being re-structured so that markets play a stronger part and public services are contracting; the role of civil society has become a key area of debate. Policy debates emphasise communities "helping themselves". Consequently, community activities and structures are the focus of debate about their role and function in society. This debate needs to be informed by information about who participates in what, as well as how and why they participate in the civil and social life of their communities. Such an epidemiology of participation will also make a significant contribution to current debates about social capital and its relation to health, well being and public policy.

In this study we have measured activities that are likely to be directly relevant to empowerment (such as taking part in a residents' action group, or signing a petition). We have also measured other activities such as informal social participation. We have been keen to do this because while the health promotion literature reviewed above concentrates on the directly empowering forms of participation, we believe there are likely to be important interactions between all forms of social and civic participation. These interactions have not been the subject of much research. We are also conscious that the literature 
Table 2 Levels of participation in social activities in public spaces, by demographic and health characteristics of respondents

\begin{tabular}{|c|c|c|c|c|}
\hline & \multicolumn{4}{|c|}{ Type of social activity in public space } \\
\hline & $\begin{array}{l}\text { Social club } \\
\%(n)\end{array}$ & $\begin{array}{l}\text { Cafe/restaurant } \\
\%(n)\end{array}$ & $\begin{array}{l}\text { Cinemaltheatre } \\
\%(n)\end{array}$ & $\begin{array}{l}\text { Party/dance } \\
\%(n)\end{array}$ \\
\hline \multicolumn{5}{|l|}{ Gender } \\
\hline Men & $30.6(338)^{\star}$ & $53.9(595)^{\star}$ & $20.4(225)^{\star}$ & $16.6(183)$ \\
\hline Women & $24.5(328)$ & $61.6(831)$ & $25.8(347)$ & $16.3(218)$ \\
\hline $\mathrm{p}$ Value & 0.001 & 0.000 & 0.002 & 0.853 \\
\hline \multicolumn{5}{|l|}{ Age } \\
\hline $18-59$ & $22.7(368)^{\star}$ & $64.2(1031)^{\star}$ & $30.3(486)^{\star}$ & $21.7(347)^{\star}$ \\
\hline $60+$ & $36.3(290)$ & $45.6(367)$ & $9.5(76)$ & $5.8(46)$ \\
\hline p Value & 0.000 & 0.000 & 0.000 & 0.000 \\
\hline \multicolumn{5}{|l|}{ Education } \\
\hline Low & $30.6(101)^{\star}$ & $33.0(109)^{\star}$ & $7.7(25)^{\star}$ & $8.0(26)^{\star}$ \\
\hline Medium & $28.2(472)$ & $58.4(979)$ & $21.5(361)$ & $16.6(277)$ \\
\hline High & $20.7(84)$ & $76.7(312)$ & $43.0(174)$ & $23.0(93)$ \\
\hline p Value & 0.001 & 0.000 & 0.000 & 0.000 \\
\hline \multicolumn{5}{|l|}{ Household income } \\
\hline$<\$ 15600$ & $29.6(225)$ & $44.1(335)^{\star}$ & $15.0(114)^{\star}$ & $13.0(99)$ \\
\hline$\$ 15600-\$ 31199$ & $29.9(160)$ & $60.4(326)$ & $26.2(141)$ & $21.3(114)$ \\
\hline$\$ 31200-\$ 46799$ & $22.8(95)$ & $61.3(257)$ & $26.7(112)$ & $17.4(72)$ \\
\hline$\$ 46800-\$ 62399$ & $27.7(66)$ & $71.5(171)$ & $26.5(63)$ & $19.2(46)$ \\
\hline$\$ 62400+$ & $21.7(62)$ & $79.1(227)$ & $36.4(104)$ & $15.1(43)$ \\
\hline p Value & 0.006 & 0.000 & 0.000 & 0.064 \\
\hline \multicolumn{5}{|l|}{ Physical health $(<60)$} \\
\hline Low & $21.6(112)$ & $54.5(282)^{\star}$ & $24.1(125)^{\star}$ & $17.1(88)^{\star}$ \\
\hline High & $23.6(242)$ & $69.2(713)$ & $33.5(345)$ & $24.3(250)$ \\
\hline $\mathrm{p}$ Value & 0.391 & 0.000 & 0.002 & 0.001 \\
\hline \multicolumn{5}{|l|}{ Physical health $(\geqslant 60)$} \\
\hline Low & 36.9 (193) & $41.8(219)^{\star}$ & $7.7(40)$ & $5.8(30)$ \\
\hline High & $35.1(78)$ & $53.6(119)$ & $13.1(29)$ & $6.3(14)$ \\
\hline $\mathrm{p}$ Value & 0.647 & 0.003 & 0.020 & 0.784 \\
\hline \multicolumn{5}{|l|}{ Mental health $(<60)$} \\
\hline Low & $18.8(66)$ & $58.6(205)$ & $30.6(107)$ & $20.9(73)$ \\
\hline High & $24.1(288)$ & $65.9(790)$ & $30.3(363)$ & $22.2(265)$ \\
\hline $\mathrm{p}$ Value & 0.034 & 0.011 & 0.923 & 0.590 \\
\hline \multicolumn{5}{|l|}{ Mental health $(\geqslant 60)$} \\
\hline Low & $34.5(49)$ & $38.5(55)$ & $5.0(7)$ & $4.3(6)$ \\
\hline High & $36.8(222)$ & 46.9 (283) & $10.3(62)$ & $6.4(38)$ \\
\hline $\mathrm{p}$ Value & 0.607 & 0.067 & 0.052 & 0.340 \\
\hline \multicolumn{5}{|l|}{ Social isolation } \\
\hline Low & $29.9(491)^{\star}$ & $61.3(1014)^{\star}$ & $24.4(402)$ & $17.4(287)$ \\
\hline High & $20.7(154)$ & $51.6(383)$ & $21.5(160)$ & $14.8(109)$ \\
\hline p Value & 0.000 & 0.000 & 0.123 & 0.105 \\
\hline Total & $27.3(666)$ & $58.1(1426)$ & $23.4(572)$ & $16.5(401)$ \\
\hline
\end{tabular}

contains many different activities under the rubric "participation". A paper by Oddy et $a l^{30}$ sees participation only as involvement in health promotion sponsored projects in sports, arts or racing. This contrasts with our understanding, which is far broader, as specified in the methodology section.

Gaining an understanding of the epidemiology of both social and civic participation is also important because of the emerging pattern of evidence that indicates that social support in itself has a positive impact on health ${ }^{31}{ }^{32}$ and that social capital (measured by trust and participation in voluntary groups) correlates with better health outcomes. ${ }^{4}$ Measures used to describe the participation aspects of social capital so far have been crude. For instance Kawachi and Kennedy ${ }^{33}$ used two items from a survey conducted by the National Opinions Research Centre. One was a response to the question as to whether "Most people can be trusted, or would most people try to take advantage of you if they got the chance" and the other was a measure of density of associational life as gauged by the per capita membership of groups (such as church groups, sports groups, fraternal organisations, trade unions). Putnam's study ${ }^{14}$ of social capital in regions of Italy judged participation by the extent of associational group membership in each region, newspaper readership and elec- toral turnout. Recent literature on social capital $^{33-35}$ and discussion on list servers ${ }^{36}$ have devoted much space to the measurement of social capital but there have been very few reports of empirical attempts to do so. ${ }^{1437}$ Studies thus far have either used very broad indicators or sought peoples' opinions or attitudes. What is missing is an epidemiology of what people say they actually do in both the social and civic spheres. Furthermore, we lack studies of regional populations from which we can estimate the difference in regional participation and its impact on health. This paper seeks to contribute to this debate by providing data about the distribution and patterns of social and civic participation. These data should contribute to emerging debates on the role of civil society and social capital in health promotion and public health and to improving the effectiveness of strategies aimed at strengthening participation.

\section{Methods}

The data reported in this paper are part of a broader study, the Health Development and Social Capital Project. These data are from a mailed questionnaire of respondents to a random sample of the population over 18 years of age conducted in the western suburbs of Adelaide, the capital city of South Australia in October 1997. The region has a lower socioeconomic status than that of the Australian population as a whole. It includes pockets of both particular advantage and disadvantage, and also has a higher than average concentration of migrants and people for whom English is not their first language. The area also has an older population than the general Australian community. $^{38}$

The questionnaire used in the study was developed using a combination of pre-existing measures and those developed specifically for this study. Health status was measured using the SF-12, ${ }^{39}$ a shortened version of the SF-36 set of questions, which provides a measure of physical and mental health status. Low physical health was described as those people who scored below 50, in which case a physical condition is expected. The cut off score for low mental health was 42 or below, where symptoms of depression could be expected. ${ }^{40}$ Mental and physical health summary scores were derived by weighting each item in the SF-12 by US general population weights (Australian weights are not currently available), but it has been found that US weights do not differ meaningfully from the scores obtained from the SF-36 using Australian weights. ${ }^{41}$ This procedure was used in the Australian Health Survey and considered by the Australian Bureau of Statistics as satisfactory. Responses to each question were weighted by a physical or mental regression weight, to compute separate mental and physical health scores. The scores were then standardised to a mean of 50 and standard deviation of 10 .

Social isolation was measured using the subscale of the Nottingham Health Profile, where a low score equates with none or low levels of social isolation. Low social isolation was 
Table 3 Levels of participation in social group activities, by demographic and health characteristics of respondents

\begin{tabular}{|c|c|c|c|c|c|c|}
\hline & \multicolumn{6}{|c|}{ Type of group hobby/sporting activity } \\
\hline & $\begin{array}{l}\text { Played sport } \% \\
(n)\end{array}$ & $\begin{array}{l}\text { Gym or } \\
\text { exercise class \% } \\
\text { (n) }\end{array}$ & $\begin{array}{l}\text { Been to a class } \\
\%(n)\end{array}$ & $\begin{array}{l}\text { Hobby group } \\
\%(n)\end{array}$ & $\begin{array}{l}\text { Self help/ } \\
\text { support } \\
\text { group \% (n) }\end{array}$ & $\begin{array}{l}\text { Singing/ acting/ } \\
\text { music group \% } \\
\text { (n) }\end{array}$ \\
\hline \multicolumn{7}{|l|}{ Gender } \\
\hline Men & $33.1(364)^{\star}$ & $14.1(156)$ & $9.2(101)^{\star}$ & $8.2(91)$ & $3.7(41)$ & $4.0(44)$ \\
\hline Women & $20.6(274)$ & $18.0(240)$ & $17.7(236)$ & $11.6(155)$ & $4.3(58)$ & $4.1(55)$ \\
\hline $\mathrm{p}$ Value & 0.000 & 0.010 & 0.000 & 0.006 & 0.432 & 0.852 \\
\hline \multicolumn{7}{|l|}{ Age } \\
\hline $18-59$ & $30.2(485)^{\star}$ & $20.6(331)^{\star}$ & $16.4(263)^{\star}$ & $10.2(164)$ & $4.0(65)$ & $4.4(70)$ \\
\hline $60+$ & $17.8(141)$ & $7.3(58)$ & $8.9(70)$ & $9.6(76)$ & $4.1(32)$ & $3.2(25)$ \\
\hline $\mathrm{p}$ Value & 0.000 & 0.000 & 0.000 & 0.647 & 0.992 & 0.165 \\
\hline \multicolumn{7}{|l|}{ Education } \\
\hline Low & $8.8(29)^{\star}$ & $4.5(15)^{\star}$ & $5.5(18)^{\star}$ & $5.5(18)^{\star}$ & $2.5(8)$ & $2.2(7)^{\star}$ \\
\hline Medium & $26.8(445)$ & $15.7(261)$ & $12.3(205)$ & $10.0(168)$ & $4.2(70)$ & $3.8(63)$ \\
\hline High & $38.6(156)$ & $28.4(115)$ & $27.2(110)$ & $13.8(56)$ & $4.9(20)$ & $6.7(27)$ \\
\hline $\mathrm{p}$ Value & 0.000 & 0.000 & 0.000 & 0.000 & 0.090 & 0.003 \\
\hline \multicolumn{7}{|l|}{ Household income } \\
\hline$<\$ 15600$ & $19.1(145)^{\star}$ & $12.0(91)^{\star}$ & $13.8(104)$ & $9.5(72)$ & $4.6(35)$ & $4.2(32)$ \\
\hline$\$ 15600-\$ 31199$ & $26.5(141)$ & $16.9(90)$ & $11.4(61)$ & $11.9(64)$ & $3.7(20)$ & $3.7(20)$ \\
\hline$\$ 31200-\$ 46799$ & $28.7(120)$ & $17.3(72)$ & $11.6(48)$ & $9.3(39)$ & $2.4(10)$ & $5.5(23)$ \\
\hline$\$ 46800-\$ 62399$ & $30.8(73)$ & $21.4(51)$ & $19.5(46)$ & $9.7(23)$ & $3.8(9)$ & $3.4(8)$ \\
\hline$\$ 62400+$ & $40.1(113)$ & $22.5(64)$ & $18.7(53)$ & $10.8(31)$ & $3.8(11)$ & $2.1(6)$ \\
\hline $\mathrm{p}$ Value & 0.000 & 0.000 & 0.054 & 0.773 & 0.252 & 0.352 \\
\hline \multicolumn{7}{|l|}{ Physical health $(<60)$} \\
\hline Low & $19.1(99)^{\star}$ & $12.1(63)^{\star}$ & $14.9(77)$ & $10.0(52)$ & $4.4(23)$ & $4.8(25)$ \\
\hline High & $36.3(374)$ & $25.1(258)$ & $17.2(176)$ & $10.2(105)$ & $4.0(41)$ & $4.3(44)$ \\
\hline $\mathrm{p}$ Value & 0.000 & 0.000 & 0.248 & 0.929 & 0.688 & 0.632 \\
\hline \multicolumn{7}{|l|}{ Physical health $(\geqslant 60)$} \\
\hline Low & $13.6(70)^{\star}$ & $6.0(31)$ & $7.9(41)$ & $8.7(45)$ & $4.3(22)$ & $3.1(16)$ \\
\hline High & $29.7(66)$ & $11.5(25)$ & $9.6(21)$ & $10.4(23)$ & $4.1(9)$ & $4.1(9)$ \\
\hline $\mathrm{p}$ Value & 0.000 & 0.010 & 0.453 & 0.485 & 0.897 & 0.500 \\
\hline \multicolumn{7}{|l|}{ Mental health $(<60)$} \\
\hline Low & $24.2(85)^{\star}$ & $20.6(72)$ & $18.6(65)$ & $9.4(33)$ & $5.1(18)$ & $5.4(19)$ \\
\hline High & $32.4(388)$ & $20.8(249)$ & $15.8(188)$ & $10.3(124)$ & $3.8(46)$ & $4.2(50)$ \\
\hline $\mathrm{p}$ Value & 0.003 & 0.939 & 0.211 & 0.614 & 0.285 & 0.315 \\
\hline \multicolumn{7}{|l|}{ Mental health $(\geqslant 60)$} \\
\hline Low & $12.8(18)$ & $4.3(6)$ & $6.3(9)$ & $5.7(8)$ & $5.7(8)$ & $2.8(4)$ \\
\hline High & $19.8(118)$ & $8.4(50)$ & $9.0(53)$ & $10.1(60)$ & $3.9(23)$ & $3.5(21)$ \\
\hline $\mathrm{p}$ Value & 0.054 & 0.097 & 0.314 & 0.105 & 0.332 & 0.681 \\
\hline \multicolumn{7}{|l|}{ Social isolation } \\
\hline Low & $29.2(479)^{\star}$ & $16.9(277)$ & $13.6(222)$ & $10.4(171)$ & $3.6(59)$ & $4.3(70)$ \\
\hline High & $20.5(151)$ & $15.4(114)$ & $14.6(108)$ & $9.2(68)$ & $5.0(37)$ & $3.8(28)$ \\
\hline $\mathrm{p}$ Value & 0.000 & 0.358 & 0.511 & 0.369 & 0.107 & 0.561 \\
\hline Total & $26.2(638)$ & $16.2(396)$ & $13.9(337)$ & $10.1(246)$ & $4.1(99)$ & $4.1(99)$ \\
\hline
\end{tabular}

${ }^{\star} \mathrm{p}<0.006$ (with Bonferroni correction of 9).

defined as a score of zero, and high as any score above this. For education level, low was defined as no formal schooling or completion of primary school only, and high as having completed a university degree or higher. Household income was derived from two questions that asked for the respondent's and their spouse's (if applicable) annual income category. The mean of each category was then taken and if there was more than one income in the household combined and then the mean taken, to arrive at a household income category. No adjustment has been made for the number of people living in the household.

Types and levels of participation were ascertained using a battery of measures. This paper will report data relating to the respondents' participation in six categories of participation: informal social contact (for example visiting family members); social contact through activities in public spaces (for example a visit to a cafe or restaurant); participation in group sports or hobbies (such as gym or exercise classes); participation in civic activity undertaken on an individual basis (such as signing a petition or writing to a politician); civic participation involving group activity (such as a trade union or residents action group); and participation in community groups that involve a mix of social and civic purposes such as service clubs.
The appendix shows the questionnaire items that make up each of these indices of participation. Several activities were listed under each category of participation. These were determined through a process of discussion between the research team that was informed by their knowledge of the literature of participation and the measurement of social capital.

Respondents indicated how regularly they had undertaken these activities over the past 12 months. For some items they indicated either that they had or had not undertaken this activity. For others they used a scale ranging from never to once a week or more. The questionnaire was piloted using a random sample of 200 residents of the western suburbs of Adelaide taken from the telephone directory. The final questionnaire was sent to 4000 residents who were selected at random from the electoral register. Up to three reminders were sent to people who were late returning their survey form. The reminders included a postcard, a letter with a second copy of the questionnaire and another postcard. Replies were received from $63.6 \%$ of the original sample. The refusal rate was $5.5 \%$ (those who informed the research team that they did not wish to participate). The remaining $30.9 \%$ represents the non-response.

Samples from electoral registers in Australia are likely to under-represent certain groups such as younger people who may not have 
Table 4 Levels of participation in individual civic activities, by demographic and health characteristics of respondents

\begin{tabular}{|c|c|c|c|c|c|c|c|}
\hline & \multicolumn{7}{|c|}{ Type of individual civic participation } \\
\hline & $\begin{array}{l}\text { Attend } \\
\text { council } \\
\text { meeting \% } \\
(n)\end{array}$ & $\begin{array}{l}\text { Written to } \\
\text { council \% } \\
\text { (n) }\end{array}$ & $\begin{array}{l}\text { Contact local } \\
M P \%(n)\end{array}$ & $\begin{array}{l}\text { Contact } \\
\text { councillor \% } \\
\text { (n) }\end{array}$ & $\begin{array}{l}\text { Signed petition } \\
\%(n)\end{array}$ & $\begin{array}{l}\text { Attend } \\
\text { protest } \\
\text { meeting \% } \\
(n)\end{array}$ & $\begin{array}{l}\text { Written } \\
\text { letter/ } \\
\text { editor \% } \\
(n)\end{array}$ \\
\hline \multicolumn{8}{|l|}{ Gender } \\
\hline Men & $3.9(44)$ & $11.4(128)$ & $11.9(133)$ & $9.1(102)$ & $37.0(415)^{\star}$ & $8.0(90)$ & $4.3(48)$ \\
\hline Women & $4.3(59)$ & $10.3(142)$ & $10.6(146)$ & $7.4(101)$ & $43.5(598)$ & $6.4(88)$ & $3.4(46)$ \\
\hline $\begin{array}{l}\mathrm{p} \text { Value } \\
\text { Age }\end{array}$ & 0.638 & 0.390 & 0.314 & 0.115 & 0.001 & 0.116 & 0.229 \\
\hline $18-59$ & $4.2(69)$ & $11.2(182)$ & $10.4(169)$ & $7.4(120)$ & $46.8(762)^{\star}$ & $8.4(137)^{\star}$ & $4.1(67)$ \\
\hline $60+$ & $3.9(32)$ & $9.7(80)$ & $12.8(105)$ & $9.5(78)$ & $28.4(235)$ & $4.5(37)$ & $3.3(27)$ \\
\hline $\mathrm{p}$ Value & 0.664 & 0.257 & 0.078 & 0.071 & 0.000 & 0.000 & 0.295 \\
\hline \multicolumn{8}{|l|}{ Education } \\
\hline Low & $4.3(15)$ & $8.5(29)^{\star}$ & $7.9(27)^{\star}$ & $6.4(22)$ & $17.2(59)^{\star}$ & $2.6(9)^{\star}$ & $1.2(4)^{\star}$ \\
\hline Medium & $3.2(55)$ & $10.0(170)$ & $10.3(176)$ & $7.9(134)$ & $40.3(687)$ & $5.6(96)$ & $2.9(50)$ \\
\hline High & $7.6(31)$ & $16.7(68)$ & $16.6(68)$ & $10.6(43)$ & $61.9(253)$ & $17.2(70)$ & $9.8(40)$ \\
\hline $\begin{array}{l}\mathrm{p} \text { Value } \\
\text { Household income }\end{array}$ & 0.038 & 0.000 & 0.000 & 0.039 & 0.000 & 0.000 & 0.000 \\
\hline \multicolumn{8}{|l|}{ Household income } \\
\hline$<\$ 15600$ & $4.1(32)$ & $6.9(54)^{\star}$ & $10.1(79)$ & $6.6(51)^{\star}$ & $31.5(247)^{\star}$ & $4.5(35)^{\star}$ & $2.4(19)^{\star}$ \\
\hline$\$ 15600-\$ 31199$ & $2.7(15)$ & $8.5(47)$ & $9.6(53)$ & $7.2(40)$ & $40.2(222)$ & $6.0(33)$ & $3.4(19)$ \\
\hline$\$ 31200-\$ 46799$ & $4.5(19)$ & $14.5(61)$ & $13.1(55)$ & $9.3(39)$ & $50.5(212)$ & $9.3(39)$ & $4.8(20)$ \\
\hline$\$ 46800-\$ 62399$ & $5.8(14)$ & $15.7(38)$ & $14.9(36)$ & $11.7(28)$ & $52.1(126)$ & $9.1(22)$ & $7.0(17)$ \\
\hline$\$ 62400+$ & $5.2(15)$ & $14.8(43)$ & $11.4(33)$ & $10.4(30)$ & $51.2(149)$ & $14.1(41)$ & $5.2(15)$ \\
\hline $\mathrm{p}$ Value & 0.243 & 0.000 & 0.073 & 0.005 & 0.000 & 0.000 & 0.001 \\
\hline \multicolumn{8}{|l|}{ Physical health $(<60)$} \\
\hline Low & $5.0(26)$ & $12.6(66)$ & $12.6(66)$ & $8.1(42)$ & $41.2(215)^{\star}$ & $7.1(37)$ & $4.6(24)$ \\
\hline High & $3.7(39)$ & $10.5(110)$ & $9.4(98)$ & $7.0(73)$ & $49.5(518)$ & $9.1(95)$ & $3.9(41)$ \\
\hline $\mathrm{p}$ Value & 0.244 & 0.213 & 0.047 & 0.430 & 0.002 & 0.185 & 0.526 \\
\hline \multicolumn{8}{|l|}{ Physical health $(\geqslant 60)$} \\
\hline Low & $2.6(14)$ & $7.5(40)^{\star}$ & $10.8(58)^{\star}$ & $7.9(42)$ & $27.0(145)$ & $3.7(20)$ & $2.2(12)$ \\
\hline High & $6.6(15)$ & $15.4(35)$ & $18.5(42)$ & $12.8(29)$ & $32.9(75)$ & $7.5(17)$ & $4.8(11)$ \\
\hline $\mathrm{p}$ Value & 0.008 & 0.001 & 0.004 & 0.033 & 0.100 & 0.028 & 0.053 \\
\hline \multicolumn{8}{|l|}{ Mental health $(<60)$} \\
\hline Low & $3.1(11)$ & $10.9(39)$ & $10.6(38)$ & $7.3(26)$ & $45.5(163)$ & $10.6(38)$ & $4.7(17)$ \\
\hline High & $4.5(17)$ & $11.3(137)$ & $10.4(126)$ & $7.4(89)$ & $47.1(570)$ & $7.8(94)$ & $4.0(48)$ \\
\hline $\mathrm{p}$ Value & 0.247 & 0.853 & 0.909 & 0.954 & 0.608 & 0.095 & 0.515 \\
\hline \multicolumn{8}{|l|}{ Mental health $(\geqslant 60)$} \\
\hline Low & $4.9(7)$ & $8.5(12)$ & $10.6(15)$ & $8.5(12)$ & $26.1(37)$ & $4.2(6)$ & $2.1(3)$ \\
\hline High & $3.5(22)$ & $10.1(63)$ & $13.7(85)$ & $9.6(59)$ & $29.4(183)$ & $5.0(31)$ & $3.2(20)$ \\
\hline $\mathrm{p}$ Value & 0.433 & 0.541 & 0.317 & 0.678 & 0.431 & 0.707 & 0.480 \\
\hline \multicolumn{8}{|l|}{ Social isolation } \\
\hline Low & $4.7(78)$ & $10.9(182)$ & $11.6(195)$ & $8.6(143)$ & $41.6(698)$ & $7.6(128)$ & $3.9(66)$ \\
\hline High & $3.3(25)$ & $10.6(81)$ & $10.4(79)$ & $7.1(54)$ & $38.8(295)$ & $6.4(49)$ & $3.2(24)$ \\
\hline $\mathrm{p}$ Value & 0.119 & 0.863 & 0.370 & 0.227 & 0.195 & 0.287 & 0.346 \\
\hline Total & $4.1(103)$ & $10.8(270)$ & $11.2(279)$ & $8.2(203)$ & $40.6(1013)$ & $7.1(178)$ & $3.8(94)$ \\
\hline
\end{tabular}

${ }^{\star} \mathrm{p}<0.006$ (with Bonferroni correction of 9).

registered to vote and non-English speaking people (because they are less likely to be eligible to vote). Compared with census data on the region, the sample was slightly skewed towards women and older people. Younger people were under-represented, as were women aged 85 and over. Apart from these minor variations the sample is representative of the demographics of the study region.

To assess the relation between participation measures and demographic characteristics two non-parametric tests were used. For all the $2 \times 2$ cross tabulations (that is age, gender, physical health, mental health and social isolation) simple Pearson $\chi^{2}$ statistics were calculated. For the ordinal variables with more than two levels (that is education level and household income) $\gamma$ was calculated so that the strength and direction of relations could be identified. For all tests a Bonferroni correction was made because of the large number of tests. The $\alpha$ level was divided by the total number of tests done on each dependent measure $(n=9)$ thereby reducing $\alpha$ to $0.05 / 9=0.0056$.

\section{Results}

This study shows that participation in social activities was far more prevalent than participation in civic activities. Very low levels of civic participation were found, especially those done in conjunction with other people. The results from this study indicate that a range of social and demographic variables significantly affects levels of participation. These are described in relation to each form of participation we identified.

INFORMAL SOCIAL PARTICIPATION

Data on the patterns of informal social participation (measuring visits from or to family members, friends or neighbours and shown in table 1) indicated that most people had regular contact with friends and family, and somewhat less than half did so with their neighbours. Women were significantly more likely to visit family than were men. People aged 60 and over were more likely to visit their neighbours than those under 60. Similarly, people with lower incomes were most likely to visit neighbours and less likely to visit or be visited by family. Those with poorer mental health and high social isolation reported less informal social interaction. Physical health status did not correlate with informal social contact.

SOCIAL PARTICIPATION IN PUBLIC SPACES

Patterns of social activity undertaken in a public space (measured by whether respondents had gone at least monthly to a social club, cafe or restaurant, cinema or theatre, party or 
Table 5 Levels of participation in collective civic activities, by demographic and health characteristics of respondents

\begin{tabular}{|c|c|c|c|c|}
\hline & \multicolumn{4}{|c|}{ Type of collective civic participation } \\
\hline & $\begin{array}{l}\text { Local } \\
\text { government \% } \\
(n)\end{array}$ & $\begin{array}{l}\text { Political } \\
\text { party, } \\
\text { campaign, } \\
\text { trade union } \\
\%(n)\end{array}$ & $\begin{array}{l}\text { Resident or } \\
\text { community } \\
\text { action group } \\
\%(n)\end{array}$ & $\begin{array}{l}\text { Campaign/action to } \\
\text { improve social/ } \\
\text { environment } \\
\text { conditions } \%(n)\end{array}$ \\
\hline \multicolumn{5}{|l|}{ Gender } \\
\hline Men & $2.5(28)$ & $5.5(62)$ & $6.1(69)$ & $5.4(61)$ \\
\hline Women & $2.2(31)$ & $3.6(50)$ & $5.6(78)$ & $5.5(76)$ \\
\hline $\mathrm{p}$ Value & 0.693 & 0.023 & 0.595 & 0.911 \\
\hline \multicolumn{5}{|l|}{ Age } \\
\hline $18-59$ & $2.5(40)$ & $5.3(86)$ & $5.3(87)$ & $5.7(93)$ \\
\hline $60+$ & $2.1(18)$ & $3.0(25)$ & $6.8(57)$ & $5.0(42)$ \\
\hline $\mathrm{p}$ Value & 0.628 & 0.009 & 0.146 & 0.456 \\
\hline \multicolumn{5}{|l|}{ Education } \\
\hline Low & $2.0(7)$ & $1.7(6)^{\star}$ & $4.3(15)^{\star}$ & $4.6(16)^{\star}$ \\
\hline Medium & $2.0(34)$ & $4.3(73)$ & $4.8(82)$ & $4.0(69)$ \\
\hline High & $4.1(17)$ & $8.1(33)$ & $11.4(47)$ & $12.2(50)$ \\
\hline \multirow{2}{*}{\multicolumn{5}{|c|}{ Household income }} \\
\hline & & & & \\
\hline$<\$ 15600$ & $2.0(16)$ & $1.9(15)^{\star}$ & $5.8(46)$ & $3.7(29)^{\star}$ \\
\hline$\$ 15600-\$ 31199$ & $1.1(6)$ & $3.8(21)$ & $2.9(16)$ & $4.3(24)$ \\
\hline$\$ 31200-\$ 46799$ & $2.9(12)$ & $6.4(27)$ & $8.0(34)$ & $6.6(28)$ \\
\hline$\$ 46800-\$ 62399$ & $2.9(7)$ & $7.0(17)$ & $5.4(13)$ & $5.0(12)$ \\
\hline$\$ 62400+$ & $3.4(10)$ & $10.0(29)$ & $10.3(30)$ & $12.5(36)$ \\
\hline $\mathrm{p}$ Value & 0.130 & 0.000 & 0.030 & 0.000 \\
\hline \multicolumn{5}{|l|}{ Physical health $(<60)$} \\
\hline Low & $2.1(11)$ & $6.3(33)$ & $5.7(30)$ & $5.3(28)$ \\
\hline High & $2.5(26)$ & $4.8(50)$ & $4.8(50)$ & $5.9(61)$ \\
\hline $\mathrm{p}$ Value & 0.628 & 0.205 & 0.434 & 0.677 \\
\hline \multicolumn{5}{|l|}{ Physical health $(\geqslant 60)$} \\
\hline Low & $2.2(12)$ & $2.4(13)$ & $6.0(33)$ & $4.2(23)$ \\
\hline High & $2.2(5)$ & $3.9(9)$ & $9.2(21)$ & $7.9(18)$ \\
\hline p Value & 0.997 & 0.232 & 0.112 & 0.036 \\
\hline \multicolumn{5}{|l|}{ Mental health $(<60)$} \\
\hline Low & $2.2(8)$ & $4.5(16)$ & $5.8(21)$ & $5.6(20)$ \\
\hline High & $2.4(29)$ & $5.5(67)$ & $4.9(59)$ & $5.7(69)$ \\
\hline $\mathrm{p}$ Value & 0.850 & 0.418 & 0.475 & 0.902 \\
\hline \multicolumn{5}{|l|}{ Mental health $(\geqslant 60)$} \\
\hline Low & $2.0(3)$ & $2.0(3)$ & $5.2(8)$ & $6.5(10)$ \\
\hline High & $2.3(14)$ & $3.1(19)$ & $7.4(46)$ & $5.0(31)$ \\
\hline $\mathrm{p}$ Value & 0.832 & 0.464 & 0.337 & 0.453 \\
\hline \multicolumn{5}{|l|}{ Social isolation } \\
\hline Low & $2.3(39)$ & $5.1(86)$ & $6.3(106)$ & $5.8(98)$ \\
\hline High & $2.3(18)$ & $3.4(26)$ & $4.7(36)$ & $4.8(37)$ \\
\hline $\mathrm{p}$ Value & 0.976 & 0.056 & 0.107 & 0.304 \\
\hline Total & $2.4(59)$ & $4.5(112)$ & $5.9(147)$ & $5.5(137)$ \\
\hline
\end{tabular}

${ }^{\star} \mathrm{p}<0.006$ (with Bonferroni correction of 9).

dance) varied significantly according to a range of demographic and health measures (table 2). The most frequently undertaken of these activities was going to a cafe or restaurant. Social club attendance was more frequently reported by men, people over 60 , and those with low levels of education. Those most likely to visit a cafe or restaurant were women, those under 60 , those with higher educational status and higher household income, those reporting better physical health status and low levels of social isolation. Similar patterns were evident for visits to a cinema or restaurant. Higher educational levels, higher income and being under 60 were particularly strong indicators of cinema or theatre visits and going to a party or dance.

PARTICIPATION IN SOCIAL GROUP HOBBY, SUPPORT OR SPORTING ACTIVITY

Participation in hobby or support groups or sporting activity was far less frequent than in informal and formal social activity (table 3 ). Being active in sport correlated significantly with being male, being under 60 years old, and having a high educational status, higher household income, reporting good physical and mental health and not being socially isolated. Attending gym or exercise classes was most common among those aged under 60 and with better physical health, and those with higher educational status and higher household income. A slightly less number of people attended hobby groups, of whom those with higher education were most likely to. Women, those aged under 60 and better educated people were the most likely to be involved in attending a class. Few people attended self help or support groups or artistic groups and the only significant patterns in the characteristics of those who did was that those with higher educational status were more likely to be involved in artistic groups.

INDIVIDUAL CIVIC PARTICIPATION

The only activity in this category that was undertaken by a significant proportion of the respondents was signing a petition, which $37 \%$ of men and $43.5 \%$ of women reported doing in the last year (see table 4). All other activities (attending council meetings, writing to the council, contacting local MPs or councillors, attending a protest meeting and writing a letter to the editor of a newspaper) were done only by a small proportion of the sample (generally less than 10 per cent). There were few significant differences although women, people under 60 and with better physical health, those with a higher education level and higher household income were more likely to sign a petition. People under 60 were more likely to have attended a protest meeting. For all activities except contacting a local councillor or attending a council meeting, those with higher levels of education were significantly more likely to have engaged in civic activity. Those with a higher income were more likely to write to the council, sign a petition and attend a protest meeting.

\section{COLLECTIVE CIVIC PARTICIPATION}

The most significant feature of the data relating to this category of participation is how few people reported involvement in civic activity involving other people (table 5). Less than 6\% of the sample reported participating in any one of these activities. A few significant differences emerge. The most highly educated were significantly more likely than those with lower educational levels to be involved in all types of collective civic participation except local government. People living in households with higher income were the most likely to be involved in political parties or trade unions, community action groups or campaigns to improve social and environmental conditions. However, even in this group participation rates were still low.

PARTICIPATION IN OTHER COMMUNITY GROUPS Involvement in school related, service clubs, ethnic groups, volunteer organisations or church was, again, not very common (table 6). Not surprisingly, school group involvement was associated with those under 60 . Older people were significantly more likely to participate in service clubs, churches and ethnic groups. Women were most likely to participate in school related or volunteer groups than men. 
Table 6 Levels of participation in other community group activities (mix of social and civic), by demographic and health characteristics of respondents

\begin{tabular}{|c|c|c|c|c|c|}
\hline & \multicolumn{5}{|c|}{ Type of community group participation } \\
\hline & $\begin{array}{l}\text { School } \\
\text { related group } \\
\%(n)\end{array}$ & $\begin{array}{l}\text { Service club } \\
\%(n)\end{array}$ & $\begin{array}{l}\text { Ethnic group } \\
\%(n)\end{array}$ & $\begin{array}{l}\text { Volunteer } \\
\text { group } \%(n)\end{array}$ & $\begin{array}{l}\text { Attended } \\
\text { church \% } \\
\text { (n) }\end{array}$ \\
\hline \multicolumn{6}{|l|}{ Gender } \\
\hline Men & $8.6(97)^{\star}$ & $5.2(58)$ & $7.3(82)$ & $10.5(118)^{\star}$ & $20.5(225)$ \\
\hline Women & $12.8(177)$ & $6.3(87)$ & $5.8(80)$ & $17.3(237)$ & $25.0(337)$ \\
\hline & \multicolumn{4}{|c|}{ Age } & 0.008 \\
\hline $18-59$ & $14.6(237)^{\star}$ & $3.7(60)^{\star}$ & $5.3(86)^{\star}$ & $13.1(211)$ & $18.5(297)^{\star}$ \\
\hline $60+$ & $3.7(31)$ & $10.2(85)$ & $8.8(74)$ & $16.5(138)$ & $31.8(254)$ \\
\hline $\begin{array}{l}\mathrm{p} \text { Value } \\
\text { Education }\end{array}$ & \multicolumn{5}{|c|}{ Education } \\
\hline Low & $2.3(8)^{\star}$ & $4.3(15)$ & $15.7(54)$ & $9.9(34)^{\star}$ & $41.0(134)^{\star}$ \\
\hline Medium & $10.6(182)$ & $6.0(103)$ & $4.4(75)$ & $14.1(240)$ & $20.1(337)$ \\
\hline High & $19.3(79)$ & $6.6(27)$ & $8.0(33)$ & $18.3(75)$ & $19.9(80)$ \\
\hline $\mathrm{p}$ Value & 0.000 & 0.192 & 0.006 & 0.001 & 0.000 \\
\hline \multicolumn{6}{|l|}{ Household income } \\
\hline$<\$ 15600$ & $6.7(53)^{\star}$ & $5.5(43)$ & $8.5(67)$ & $14.8(116)$ & $26.7(204)^{\star}$ \\
\hline$\$ 15600-\$ 31199$ & $10.1(56)$ & $5.7(32)$ & $6.1(34)$ & $15.0(83)$ & $24.0(128)$ \\
\hline$\$ 31200-\$ 46799$ & $12.3(52)$ & $6.9(29)$ & $6.4(27)$ & $14.5(61)$ & $20.4(85)$ \\
\hline$\$ 46800-\$ 62399$ & $16.7(40)$ & $5.4(13)$ & $5.4(13)$ & $12.1(29)$ & $18.1(43)$ \\
\hline$\$ 62400+$ & $18.7(54)$ & $5.5(16)$ & $4.1(12)$ & $12.5(36)$ & $15.1(43)$ \\
\hline $\begin{array}{l}\mathrm{p} \text { Value } \\
\text { Physical health }(<60)\end{array}$ & 0.000 & 0.747 & 0.006 & 0.259 & 0.000 \\
\hline Low & $13.3(70)$ & $3.4(18)$ & $6.3(33)$ & $13.3(69)$ & $18.6(97)$ \\
\hline High & $15.7(167)$ & $3.9(41)$ & $4.9(51)$ & $12.8(133)$ & $18.4(189)$ \\
\hline $\begin{array}{l}\mathrm{p} \text { Value } \\
\text { Physical health }(\geqslant 60)\end{array}$ & 0.220 & 0.619 & 0.247 & 0.779 & 0.932 \\
\hline Low & $3.3(18)$ & $9.1(50)$ & $9.9(54)$ & $14.5(79)$ & $32.9(171)$ \\
\hline High & $5.7(13)$ & $13.3(30)$ & $4.8(11)$ & $22.0(50)$ & $27.6(61)$ \\
\hline \multicolumn{6}{|l|}{ Mental health $(<60)$} \\
\hline Low & $11.4(41)$ & $3.3(12)$ & $5.8(21)$ & $13.3(47)$ & $16.0(56)$ \\
\hline High & $15.9(192)$ & $3.9(47)$ & $5.2(63)$ & $12.9(155)$ & $19.2(230)$ \\
\hline $\begin{array}{l}\mathrm{p} \text { Value } \\
\text { Mental health }(\geqslant 60)\end{array}$ & 0.034 & 0.632 & 0.651 & 0.851 & 0.171 \\
\hline Low & $3.2(5)$ & $7.8(12)$ & $9.8(15)$ & $13.1(20)$ & $33.3(46)$ \\
\hline High & $4.2(26)$ & $11.0(68)$ & $8.0(50)$ & $17.6(109)$ & $30.9(186)$ \\
\hline $\mathrm{p}$ Value & 0.599 & 0.244 & 0.480 & 0.180 & 0.578 \\
\hline \multicolumn{6}{|l|}{ Social isolation } \\
\hline Low & $12.1(203)$ & $6.7(112)$ & $6.4(108)$ & $14.4(240)$ & $23.8(391)$ \\
\hline High & $9.1(70)$ & $4.0(31)$ & $6.3(48)$ & $13.9(106)$ & $20.3(151)$ \\
\hline $\mathrm{p}$ Value & 0.027 & 0.010 & 0.867 & 0.736 & 0.062 \\
\hline Total & $10.9(274)$ & $5.8(145)$ & $6.5(162)$ & $14.2(355)$ & $23.0(562)$ \\
\hline
\end{tabular}

${ }^{\star} \mathrm{p}<0.006$ (with Bonferroni correction of 9).

Church attendance was most strongly associated with lower educational attainment, being older and having a lower income. Participation in an ethnic group was also associated with age and lower educational level, while school related group involvement was associated with higher income, and volunteer group involvement with higher education levels.

\section{LOW PARTICIPATORS}

An analysis was done to determine the characteristics of low participators. These were defined as any person who scored in the bottom third of all six participation indices. Three hundred and forty respondents (13.6\%) fell in to this category. Women were significantly less likely $(\mathrm{p}<0.05)$ to be "low participators". At all ages "low participators" were in a minority but the proportion of "low participators" increased with age from $4.7 \%(n=8)$ of $18-24$ year olds, to $9.6 \%(n=41)$ of $35-44$ year olds and $17.6 \%(n=117)$ of people aged over 65. Those with higher educational qualifications were far less likely to be "low participators". Of those with low educational qualifications, $21.6 \%(n=77)$ were low participators compared with $14.2 \%(n=244)$ of those with medium educational level and just $3.4 \%$ $(n=14)$ of those with high educational levels. Similar patterns were present in terms of household income. This is illustrated by comparing the lowest household income group where $17.6 \%(n=142)$ were classified as low participators compared with $6.3 \%(n=9)$ of the highest income group. The differences in income and educational group were both significant $(p<0.0001)$.

Marital status had a significant effect on the distribution of low participators. Of those who had never been married (who are likely to be younger) $8.4 \%(\mathrm{n}=37)$ were low participators, compared with $13.3 \%(n=209)$ of people who were married or defacto, $33.6 \%(n=195)$ of those widowed and $47.5 \%(n=202)$ of divorced or separated people. Significant differences among low participators were also noted in the numbers of people with low mental health status $(17.3 \%, \mathrm{n}=91 \mathrm{p}<0.01)$ and low physical health scores $(16.9 \% \mathrm{n}=187 \mathrm{p}<0.0001)$. Lower rates of $12.2 \%(n=231)$ and $10.3 \%(n=135)$ respectively for those with high mental and physical health scores were evident. Not surprisingly those scoring high on the social isolation score were more likely to report low participation $(17.9 \% \mathrm{n}=140$ compared with $11.2 \% \mathrm{n}=190 \mathrm{p}<0.0001)$. This does mean, however, that $82 \%(n=640)$ of those scoring high on the social isolation scale did not emerge as low participators.

\section{Discussion}

This preliminary epidemiology of participation has highlighted some interesting patterns of participation and makes a step towards understanding the dynamics of participation in an Australian community by describing who participates in what activities. It has also highlighted the complexity of measuring social and civic participation at a population level. A major theme that emerged from this study was the relative lack of involvement of people with low income and educational level in social and civic activities. This lack of participation seems to be a further expression of a range of disadvantage that combines to exclude people from being active participators in their societies. The study also confirms the value of considering both social and civic participation. Both contribute to the development of trust and networks that form the basis of social capital.

These data indicate that participation is socially patterned and that there are groups within the community for whom social exclusion is likely to be more prevalent. In some cases explanations for these patterns can be found in terms of immediately evident lifestyle factors. For example, older people are probably more likely to visit their neighbours because they typically spend more time at home and so have greater opportunity. They may also be more dependent on their neighbours for support. Similarly people with higher education are also likely to have a higher income and so be more able to use cafes and restaurants. Educational level is a key indicator of participation. The means by which lower educational level translates to lower social and civic participation are not entirely clear. It is likely that education provides people with skills that facilitate their participation in civic concerns. 
But this pattern does indicate the way in which one form of disadvantage translates into a package of disadvantage when aggregated with other factors. Together these can create a situation in which people are excluded from both social and civic activity. This exclusion is likely to have an association with poorer health as the data suggest.

Gender and age clearly exert a significant influence on patterns and types of participation. Gender seems to make most difference in terms of social participation. Women emerge as being engaged in more social activity than men. The only social activities that men do more than women is attending a social club and playing sport. Types of civic and community group participation seem to be related to age. Older people are more likely to attend church and service clubs or to belong to a volunteer group. Those under 60 are more likely to be involved through schools and political parties or trade unions. In all cases, however, the levels of civic participation are very low. Younger people are more likely to report social contact than those over 60 with the exception of visiting neighbours or attending a social club. These data are tantalising because they suggest these distinctive patterns but provide few clues about the reasons for the differences. None the less it is important to document them because so much literature on participation treats communities as if they are homogenous. These data suggest there are distinct patterns that shape experiences of social and civic participation and that these patterns are associated with physical and mental health as well. The gender differences, in particular, require further exploration. Some authors ${ }^{13}{ }^{42}$ have warned of the danger that women may be the ones who assume the responsibility for building social capital in their communities, to the detriment of their health. Conversely, the higher participation rates may be one factor contributing to women's longevity, compared with men.

Overall these data indicate that mental health status is more strongly correlated with participation than physical health status. Physical health may be more of a deterrent to participation once people are over 60 years old, when low physical health status is more likely to be a reflection of long term chronic conditions. The relation with health is complex. On the one hand, ill health can act as a barrier to participation. On the other hand, participation may also improve health.

The low levels of civic participation reported in this study raise many issues for health policy makers and programme developers, who advocate participation as a key strategy to achieve community input to health policies and health programmes. Of particular concern is the concentration of low participators among socially disadvantaged groups. Their current lack of involvement in civic activities and the concentration of those who do among the more socially advantaged indicates that there is considerable potential for increasing the opportunities and support that may enable the socially disadvantaged to participate in civic activities and so increasing peoples' sense of empower-
KEY POINTS

- Public health and health promotion literature recognises the importance of community participation for empowerment and health, but few studies have examined the prevalence and patterns of participation across a population. This paper seeks to contribute to understanding the epidemiology of participation.

- Recent debates on public policy, including health policy, have emphasised the importance of social capital and participation.

- Levels of civic participation in this Australian suburban population are low.

- Levels of civic and social participation are structured according to key socioeconomic variables.

- These data on levels of participation are important to health planning and health promotion practice.

ment. However, it should also be considered that low income people may not have resources to participate in civic activities if they are struggling to survive. If, as Labonte ${ }^{2122}$ and Israel et $a t^{4}$ argue, empowerment is beneficial for health, then a campaign, supported by health services, to increase involvement in civic activities that gives people a sense of gaining more power over their lives could have worthwhile health promoting outcomes. Participation in health system activity such as planning, resource allocation and evaluation is likely to be more equitable and efficient if community members are involved in these processes. The relatively low levels of participation reported in this study suggests that health systems will have to devise means of supporting people and increasing the opportunities for them to participate. This is especially the case for those with low educational levels and low incomes, who need assistance in acquiring the skills, confidence and motivation to participate in civic activity. The study also suggests that a society where people have access to educational opportunities is likely to be one with higher participation rates. We are conscious that participation is not a substitute for policy measures to reduce material disadvantage. Reducing inequities itself, is likely to be one of the most effective means of encouraging broader civic participation.

The implications of the package of disadvantage (low educational level, low income) that seems to lead to social exclusion is highly significant for public health policy and practice. It implies that an important project for public health practitioners is to find means of reducing social exclusion. This may partly be achieved through local actions at community health centres but will also require broader scale public policy interventions. The local action is likely to centre on community development activities such as the provision of support groups and neighbourhood meeting places to encourage social interaction in a way 
that does not require much expenditure. District health councils ${ }^{43}$ are an example of a local supportive structure established by health systems. Broader policies will concern the provision of a strong public education sector, a more equitable distribution of income and resources, and a focus on providing resources to regions identified as having higher than average numbers of their residents who are excluded from social and civic participation and from access to the resources that support this participation.

The study reported in this paper has established that participation in social and civic activities reflects distinct patterns in terms of health status, income, gender, and educational attainment. It does not, however, provide much insight into why these patterns exist. Typical of the dilemmas raised by this study is finding an explanation of why the divorced and widowed emerged as a group of extremely low participators. One explanation might be that people who are not part of a couple are somewhat excluded in a society in which couples are viewed as the norm. It may also reflect the complexities of managing a divorce period and, for those with children, the constraints that single parenthood places on participation outside the home. However, these descriptive data cannot illuminate such causal issues.

We hope to gain more insight to the issues raised in this study through the next stage of the Adelaide Health Development and Social Capital study. This stage has entailed in depth interviews with 40 of the respondents from the mailed questionnaire survey who indicated they were willing to discuss the issues of participation in more detail. Twenty of these were high participators and 20 were low participators. These qualitative data will shed light on the experience of participation and provide detailed information on reasons why people do or do not participate in social and civil activity.

Another part of the study is producing an inventory of community groups and organisations in the region and case studies of 25 of these structures are also being compiled. These will allow an analysis of the community structures within the study region. It will also permit analysis of the potential role of existing groups, which usually have a mix of social and civic functions, as a mechanism to increase community participation in civic and social activity and explore the ways in which health and other government sectors might support these groups.

This analysis will enable us to explore the notion of how health services may achieve better health outcomes, including investing their efforts in increasing community participation and developing partnerships with existing local groups and organisations. Stronger partnerships between existing community organisations and groups could be mutually beneficial for the groups and the health services, the evidence for which will appear in the associations of social and civic participation and measures of population health status.
It is unlikely that a single set of data can fully elucidate the complexities of individuals' choice about participation and the ways in which they are constrained by social, cultural and economic environments. For us this epidemiology of participation has provided an important initial step in trying to put together the complicated jigsaw puzzle of social capital. While some hints are indicated for policy direction further knowledge is desirable. For instance it was intriguing that social club use was the type of participation that seemed to be more frequent among those who, on most other measures, were low participators: older people, men, the less well educated and the socially isolated. These data beg fascinating questions about whether investing in the development of social clubs might be a way in which the participation of low participators could be increased at least in the locality where the study was conducted.

Further studies using similar measures would permit comparisons of participation levels in different communities around the world. This will be an important step to increase understanding of the ways in which participation levels differ in different contexts and cultures. Given that the level of social capital is being seen as an important indicator of a healthy community despite the fact that the mechanisms for measuring it are relatively crude and certainly not agreed upon, it is important to establish a body of empirical and theoretical literature. Thus, understanding the patterns underpinning social and civic participation will be important to social and health policy debates. Crucial messages for policy makers are that social capital and its constituent community process such as social and civic participation are extremely complex, reflect existing patterns of social disadvantage and are not well suited to "quick and dirty" measurement. The implications of these messages are that our knowledge of social and civic participation will only be converted into meaningful social and health policy if these are informed by an understanding of the processes by which people make decisions about their own social and civic participation and how these decisions are constrained by their social and economic circumstances.

An Advisory Committee has advised the project and the researchers would like to acknowledge their contribution to the study.

Funding: this study was funded by the Public Health Research and Development Committee of the Australian National Health and Medical Research Council. This study was funded by the and Medical Research Council. This study was funded by the
Public Health Research and Development Committee of the Public Health Research and Development Committee of
Australian National Health and Medical Research Council. Australian National Health
Conflicts of interest: none.

\section{Appendix}

Activities contained in each Index of Participation from the Survey Social participation-informal (3 items)

If the respondent had done any of the following activities monthly or more in the past twelve months:

Visited family or had family visit; visited friends or had friends visit; visited neighbours or had neighbours visit. 
Social participation-in public spaces (4 items)

If the respondent had done any of the following activities monthly or more in the past twelve months:

Been to a cafe or restaurant; been to a social club; been to the cinema or theatre; been to a party or dance.

Social participation-group activities (6 items)

If the respondent had done any of the following activities monthly or more in the past twelve months:

Played sport; been to the gym or exercise class; been to a class; been involved in a hobby group; singing/acting/musician in a group; been involved in a self help or support group.

Civic participation-individual activities ( 7 items)

If the respondent had done any of the following activities at all in the past twelve months:

Signed a petition; contacted a local MP; written to the council; contacted a local councillor; attended a protest meeting; written a letter to the editor of a newspaper; attended a council meeting.

Civic participation-group activities (4 items)

If the respondent had been involved in any of the following groups at all in the past twelve months:

Resident or community action group; political party, trade union or political campaign; campaign or action to improve social or environmental conditions; local government.

Community group participation-mix of social and civic ( 5 items)

If the respondent had been involved in any of the following groups at all in the past twelve months:

Volunteer organisation or group; school related group; ethnic group; service club, attended church monthly or more often.

1 World Health Organisation. Global Strategy for Health for All by the Year 2000. Geneva: World Health Organisation, by the

2 World Health Organisation. Ottawa Charter for Health Promotion. Health Promotion 1986;1:i-v.

3 World Health Organisation. The fakarta Declaration on leading health promotion into the 21st century. Geneva: World . 1997.

4 Kawachi I, Kennedy BP, Lochner K, et al. Social capital, income inequality, and mortality. Am 7 Public Health 1997; 87:1491-8.

5 Ziguras SA. Passport to health and participation. Сотmunity Quarterly 1992;24:15-20.

6 Rifkin S. Lessons from community participation in health programmes. Health Policy and Planning 1986;1:240-9.

Lipsky M, Lounds M. Citizen participation and health care: problems of government and induced participation. $f$ Health Polit Policy Law 1976;1:85-111.

8 Oakley P. Community involvement in health development: an examination of the critical issues. Geneva: World Health Organisation, 1989

9 Legge D. Community participation: models and dilemmas. In: Kaplan L, ed: Making the connections-people, communities and the environment. First National Conference of Healthy Cities Australia. Wollongong: Australian Community Health Association, 1990

10 Baum FE. Measuring effectiveness in community-based health promotion. In: Davies JK, Macdonald G, eds. Qualhealth promotion. In: Davies JK, Macdonald G, eds. Qual1998 .

11 Baum FE. The new public health: An Australian perspective. Melbourne, Australia: Oxford University Press, 1998:326.
12 Oakley P. Community involvement in health development: an examination of the critical issues. Geneva: World Health

13 Cox E. A truly civil society. Sydney, Australia: Australian Broadcasting Commission, 1995

14 Putnam RD. Making democracy work: civic traditions in modern Italy. New Jersey: Princeton University Press, 1993.

15 Verba S, Schlozman KL, Brady HE. Voice and equity: civic voluntarism in American politics. London: Harvard University Press, 1995.

16 McKnight JL. Health and empowerment. Can 7 Public Health 1985;76:37-8.

17 Freire P. Pedagogy of the oppressed. Harmondsworth: Penguin, 1972.

18 Ife J. Community development. Creating community alternatives-vision, analysis and practice. Melbourne: Longman, 1995

19 Community Development in Health. Community development in health: resource collection. Melbourne: Community Development in Health, 1988.

20 Wallerstein N. Powerlessness, empowerment and health: implications for health promotion programs. Am f Health Promot 1992;6:197-205.

21 Labonte R. Empowerment: notes on professional and community dimensions. Can Rev Soc Policy 1990;6:1-12.

22 Labonte R. Power, participation and partnerships for health promotion. Melbourne: VicHealth, 1997.

23 Tones K. Health promotion, self-empowerment and the concept of control. In: Colquhoun D, ed. Health education: politics and practice. Geelong, Victoria: Deakin University, 1992

24 Israel B, Checkoway B, Schulz A, et al. Health education and community empowerment: conceptualizing and measuring perceptions of individual, organizational and community control. Health Educ Q 1994;21:149-70.

25 Rissel C. Empowerment: the holy grail of health promotion. Health Promotion 1994;9:39-47.

26 Rappaport J. Terms of empowerment/exemplars or prevention: towards a theory for community psychology. Am $\mathcal{f}$ Community Psychol 1987;15:121-48.

27 Zimmerman MA. Taking aim on empowerment research: on the distinction between individual and psychological conceptions. Am f Community Psychol 1990;18:169-77.

28 Hawe P. Capturing the meaning of "community" in community intervention evaluation: some contributions from community psychology. Health Promotion 1994;9: 199-210

29 Israel B, Checkoway B, Schulz A, et al. Health education and community empowerment: conceptualizing and measuring perceptions of individual, organizational and community control. Health Educ $Q$ 1994;21:153.

30 Oddy WH, Holman CDJ, Corti B, et al. Epidemiological measures of participation in community health promotion projects. Int $\mathcal{F}$ Epidemiol 1995;24:1013-21.

31 Rosenfeld ER. Social support and health status: a literature review. Adelaide, South Australia: South Australian Community Health Research Unit, 1997.

32 House J, Landis K, Umberson D. Social relationships and health. Science 1988;241:540-5.

33 Kawachi I, Kennedy B. Socio-economic determinants of health: health and social cohesion: why care about income inequality, BMF 1997;314:1037-40.

34 Veenstra G, Lomas J. Home is where the governing is: social capital and regional health governance. Health and Place 1999;5:1-12.

35 Knack S, Keefer P. Does social capital have an economic payoff? A cross-country investigation. Quarterly fournal of Economics 1997;112:1251-88.

36 Website and listservs-University of Technology Sydney: www.uts.edu.au/fac/hss/socialcapital/, Listserv majordoma @uts.edu.au, subscribe socapnet. World Bank: www. worldbank.org/, Listserv listserv@tome.worldbank.org, subscribe socialcapital.

37 Onyx J, Bullen P. Measuring social capital in five communities in NSW: an analysis. Sydney: Centre for Australian Community Organisations and Management, 1997.

38 Australian Bureau of Statistics. 1996 Census Data. http:// www.abs.gov.au/1966.

39 Ware JE, Kosinski M, Keller SD. SF-12: How to score the SF-36 physical and mental health summary scales. Boston, MA: New England Medical Center, 1995.

40 Ware JE, Kosinski M, Keller SD. SF-36 physical and mental health summary scales: a user's manual. Boston, MA: New England Medical Center, 1997.

41 Wilson D, Parsons J, Taylor A. Physical and mental health status of the Northern Adelaide Health Planning Area. Adelaide: Behavioural Epidemiology Unit, South Australian Health Commission, 1996.

42 Portes A, Landolt P. The downside of social capital. The American Prospect 1996;26:18-21.

43 Baum F, Sanderson C, Jolley G. Community participation in action: an analysis of the South Australian Health and Social Welfare Councils. Health Promotion 1997;12:12534. 